\title{
Three-dimensional P-wave velocity struc- ture of the crust beneath Hainan Island and its adjacent regions, China*
}

\author{
LI Zhi-xiong $^{1)}$ (李志雄) LEI Jian-she ${ }^{2), \uparrow}$ (雷建设) ZHAO Da-peng ${ }^{3)}$ (赵大鹏) \\ WU Bateer ${ }^{4}$ (武巴特尔) SHEN Fan-luan ${ }^{1)}$ (沈繁銮) QIU Xue-lin ${ }^{5}$ (丘学林)
}

1) Earthquake Administration of Hainan Province, Haikou 570203, China

2) Institute of Crustal Dynamics, China Earthquake Administration, Beijing 100085, China

3) Department of Geophysics, Tohoku University, Sendai 980-8758, Japan

4) College of Prevention Disaster Technology, Sanhe 101601, China

5) South China Sea Institute of Oceanology, Chinese Academy of Sciences, Guangzhou 510301, China

\begin{abstract}
Using over 3500 first P arrival times recorded by nine digital seismic stations from Hainan Digital Seismic Network during 1999 2005, a 3-D P-wave velocity model of the crust under Hainan Island and adjacent regions has been determined. The results show that the pattern of velocity anomalies in the shallower upper crust is somewhat associated with the surface geological tectonics in the region. A relative low-velocity anomaly appears north of the Wangwu-Wenjiao fault zone and a relative high-velocity anomaly appears south of the Wangwu-Wenjiao fault zone, corresponding to the depressed areas in north Hainan Island, where many volcanoes are frequently active and geothermal values are relatively higher, and the uplifted and stable regions in central and south of the Hainan Island. In the middle and lower crust velocities are relatively lower in east Hainan than those in west Hainan, possibly suggesting the existence of the upwelling of hot materials from the mantle in east Hainan. The pattern of velocity anomalies also indicates that NW faults, i.e., the Puqian-Qinglan fault, may be shallower, while the E-W Wangwu-Wenjiao fault may be deeper, which perhaps extends down to Moho depth or deeper.
\end{abstract}

Key words: 3-D velocity; P-wave; crustal structure; Hainan Island

CLC number: P315.3 Document code: A

\section{Introduction}

The Hainan Island and adjacent regions are situated on the southeastern margin of the Eurasian Plate, which were influenced by the movement of the Indian and Philippines Sea plates and the extension of the South China Sea basin. Among them, the extension of the South China Sea basin has been making the most important contribution to the regional tectonic framework. Therefore, the tectonic movement, volcanism, and seismic activities in the region are all intense. The South China Sea is a back-arc basin after the extension that is approximately in the west-east

\footnotetext{
* Received 2008-03-20; accepted in revised form 2008-07-10.

Foundation item: The special project of Detection of Haikou City Earthquake Active Faults from the Tenth Five-year Plan of China Earthquake Administration (0106512), Joint Seismological Science Foundation of China (105086) and CAS Key Laboratory of Marginal Sea Geology (MSGL0503).

^Author for correspondence: leijs@hotmail.com
} 
direction. The extension of the South China Sea finally led to a series of west-east oriented uplifts, depressions, and dextral fault zones in the sea area, and continued northwardly to the continent. Furthermore, a series of approximately west-east oriented, deep and large fault zones were formed in the Lei-Qiong region, and the Lei-Qiong graben is so far a huge rift fault zone (LI, 1991; JIANG and LI, 1994).

There are mainly two groups of the active faults in the Hainan Island and its adjacent area. One is nearly west-east oriented, while the other is northwest oriented (Figure 1). In addition, there are still some northeast and other oriented fault zones. The west-east oriented fault zones are tensional, deep and huge, such as the Wangwu-Wenjiao, Jianfeng-Diaoluo, and Jiusuo-Lingshui fault zones, which controls the distributions of depressions, uplifts and volcanic rocks in the Hainan Island. The west-east oriented Wangwu-Wenjiao fault zone is a boundary between the Lei-Qiong graben and uplifted regions in the central-south portion of Hainan Island. Toward the north to the northern Hainan and Leizhou region, the Quaternary volcanisms are active and seismic activities are intensive. Toward the south to the west-east oriented Jianfeng-Diaoluo faults, seismic activities are relatively quiet. Further southward the seismic activities become frequent, where many moderate-size earthquakes occurred and earthquake swarms were formed (HU et al, 1997; CHEN et al, 2002).

North of the Wangwu-Wenjiao fault zone the NW oriented fault zones are neogenic and intensively active, which controlled the distribution of the latest volcanic activity and the Cenozoic stratum. Their separations are evenly as large as $30 \sim 40 \mathrm{~km}$, such as the Puqian-Qinglan, Changliu-Xiangou, and Haikou-Yunlong fault zones in north Hainan. The north-west oriented fault zones generated earthquakes, such as the 1605 Qiongshan earthquake (M7.5), the 1994 Beibu gulf earthquake (M6.1), and the 1995 Beibu gulf earthquake (M6.2). The intersections of the NW and $\mathrm{W}-\mathrm{E}$ oriented active tectonic zones are some main sites where strong earthquake occurred. As early as in 1988 previous researchers conducted some investigations of the tectonics and seismic activities in north Hainan, and published a certain depth, comparatively overall, systemic and authoritative treatise (DING et al, 1988). Based on the previous studies, a seismic tomographic technique has been used in the present study to detect a fine velocity structure under Hainan and adjacent regions to further analyze the relationship among faults, earthquakes, and velocity structures, which provides basic data for better understanding some latest deep dynamic processes, specially for prevention measures against strong earthquake occurrence and volcanic eruption and mitigating disasters in the Haikou and adjacent regions.

\section{Data and method}

Figure 1 shows the distribution of nine seismic stations in Hainan Island and adjacent regions. Most of them are distributed on north Hainan, while they are sparse (only SYA) in west and (only DFG) south Hainan. The 464 local earthquakes (Figure 1) were selected from May 1999 to October 2005 and recorded by at least five seismic stations. Over 3500 high-quality first P-wave arrival times were collected, and their travel-time residuals are all less than $5.0 \mathrm{~s}$. These events were relocated by using the double difference method of Waldhauser and Ellsworth (2000). The results showed the standard deviations of more than $90 \%$ earthquakes are less than $2.5 \mathrm{~km}$ in the longitude, latitude, and depth directions, and most events in northeast and southeast Hainan are less than $2.0 \mathrm{~km}$, while the accuracy is slightly poorer but less than $5.0 \mathrm{~km}$ when the events occurred in the Beibu gulf. It is found from the spatial distribution of the earthquakes (Figure 1) that 
the earthquakes mainly occurred on the margin of Hainan and seldom in central Hainan.

In this study we used a tomographic technique developed by Zhao et al (1992). To calculate travel times and ray paths more accurately, a 1-D initial velocity model and undulated Moho discontinuity suited for the region are adopted. These models are summarized from previous studies (DING et al, 2004; JIA et al, 2006; LI et al, 2006). The Moho discontinuity varies dramatically, which is, about $30 \mathrm{~km}$ deep, deeper in central and south Hainan, but become gradually shallower, about 23 24 km deep, under north Hainan and Qiongzhou strait. As for details of the Moho discontinuity, see LI et al (2006). A large number of the checkerboard resolution tests showed that the model is optimally parameterized with an interval of

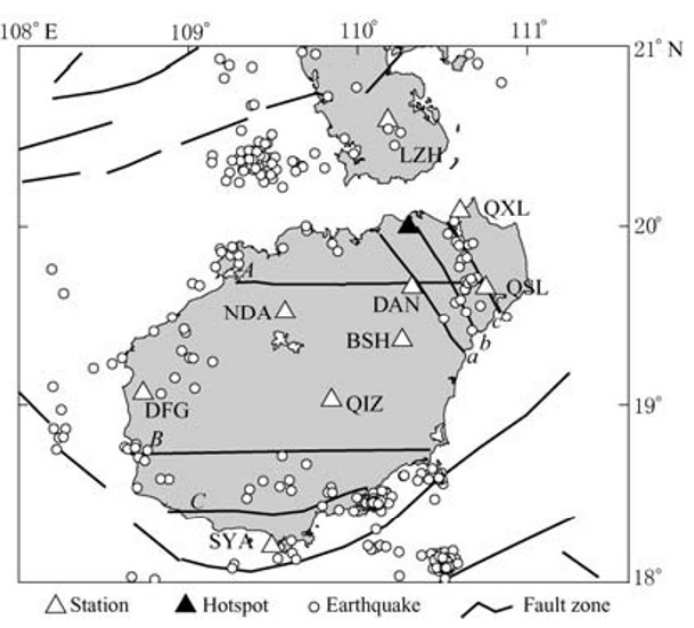

Figure 1 Distribution of seismic stations and earthquakes used in this study and major fault zones

$A$ Wangwu-Wenjiao fault zone; $B$. Jianfeng-Diaoluo fault zone; $C$. Jiusuo-Lingshui fault zone. $a$. Changliu-Xiangou fault zone; $b$. Haikou-Yunlong fault zone; $c$. Puqian-Qingnan fault zone

$0.5^{\circ} \times 0.5^{\circ}$ in horizontal directions, and layer depths are $1,5,10,15,25$ and $35 \mathrm{~km}$ in vertical direction (Figure 2). The velocity of a point in the modeling space can be interpolated by using those of eight nodes around it (Zhao et al, 1992; Zhao and Lei, 2004). The velocity perturbations of grid nodes were takes as unknowns. The inversion technique used in the study is the least squares (Paige and Saunders, 1982) with damping and smoothing regulations (Zhao, 2001; Lei and Zhao, 2006).

\section{Results and resolution analyses}

Figure 2a 2f shows our obtained tomographic results in map view. At shallow depths, the velocity anomalies are somewhat associated with surface geological tectonics. For example, at $1 \mathrm{~km}$ depth there is an obvious west-east boundary between high- and low-velocity anomalies, but the velocity anomalies are also characterized by the west-east oriented Wangwu-Wenjiao fault zone. In north Hainan and Qiongzhou strait there are obvious low velocity anomalies, which may be related to the distribution of volcanic eruptions (Figure 2a). At $10 \mathrm{~km}$ depth the whole Hainan shows a relatively high-velocity anomaly (Figure 2c). At $25 \mathrm{~km}$ depth there are obvious low-velocity anomalies in central and north Hainan, while the margins show obvious high-velocity anomalies, which may reflect the structural differences between continental and oceanic areas (Figure 2e). In the uppermost mantle (at $35 \mathrm{~km}$ depth), there are obvious low-velocity anomalies in east Hainan, while prominent high-velocity anomalies in west Hainan, which may reflect the structural differences between east and west Hainan (Figure 2f ). In addition, low-velocity anomalies are associated with the distribution of fault zones, which may reflect the broken belts on crustal or lithospheric scales.

There are many hotspots on the Earth, which show obvious tectonic characteristics, such as topographic swell, higher temperature, and recent volcanism with isotopic signatures distinct from 

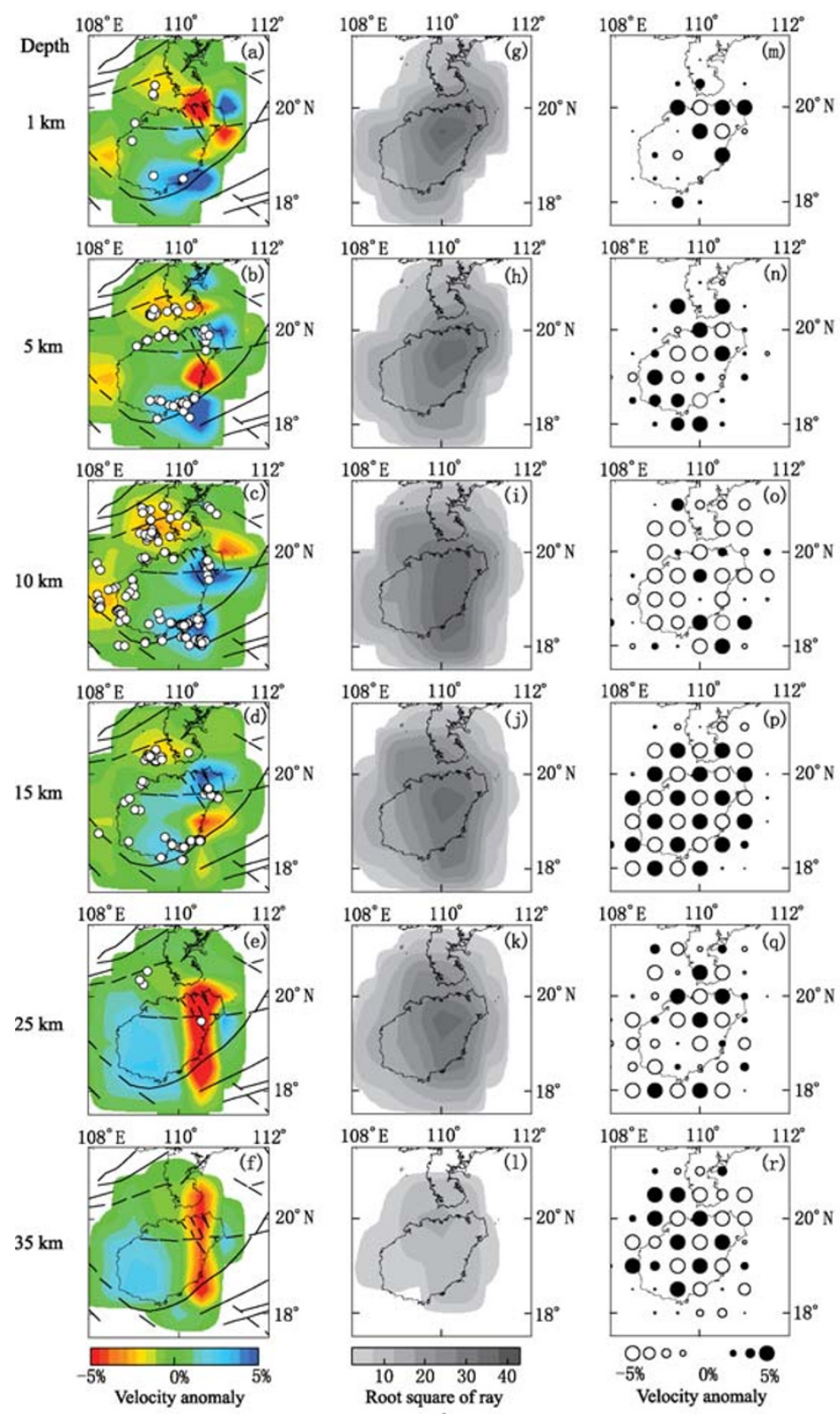

Figure 2 (a) (f) 3-D P-wave velocity anomalies in map view under Hainan and adjacent areas. (g) (l) The number of rays. (m) (r) The results of a checkerboard resolution test

In (a)-(f) red and blue colors denote slow and fast velocity anomalies. Velocity perturbation scale in percent is shown on the bottom of (f). Black lines denote major fault zones. In (g)-(1) white and black colors denote the root square of the number of rays. The scale for the number of rays is shown on the bottom of (1). In (m)-(r) solid and open circles denote fast and slow velocity anomalies. The perturbation scale is shown on the bottom of (r)

those that characterize mid-oceanic ridge or andesitic basalts (Davies, 1988; Sleep, 1990; Courtillot et al, 2003). In present studying region, north Hainan is called a hotspot (Lebedev et al, 2000). From the vertical cross-sections (Figure 3 ) we can see clearly that there is an obvious low-velocity anomaly under the Hainan hotspot down to $5 \mathrm{~km}$ depth, lower crust, and to the uppermost mantle, and the shape of the low-velocity anomaly is consistent with the Moho uplift, reflecting the up- 
welling of some hot materials from the mantle.

The checkerboard resolution test is an efficient way to detect the crisscrossing of rays in the region and to determine whether unknown parameters set up in the modeling space can be resolved well by using this data set. The detailed procedure is as follows. Firstly, a velocity model with alternating positive and negative anomalies is constructed, and in this model the theoretical travel times and ray paths are calculated based on the actual locations of hypocenters and seismic stations; Secondly, the travel times are computed in the model without alternating positive and negative anomalies; Thirdly, based on the travel time residuals calculated from these two models, using the same inversion method as used in a real data set, a velocity model with alternating positive and negative anomalies is obtained; Finally, the resolution is judged to be good or not, depending on the recovering degree of the model with alternating positive and negative anomalies. In this study, the velocity perturbation is $5 \%$. From the results of the checkerboard resolution in map view, we can see that in north Hainan the pattern of velocity anomalies is recovered (Figures $2 \mathrm{~m} \sim 2 \mathrm{o}$ and $2 \mathrm{q}$ ) except for those at $10 \mathrm{~km}$ depth (Figure 2o). In particular, at depths of $15 \mathrm{~km}$ and $35 \mathrm{~km}$ the pattern and amplitude of anomalies are well recovered (Figures $2 \mathrm{p}$ and $2 \mathrm{r}$ ). From the resolution of the vertical cross-sections we can see that the pattern of the resolution is all recovered well except for a small number of anomalies in some grid nodes around $110^{\circ} \mathrm{E}$ in the cross-section W-E (Figures 3e and 3f). Particularly, the amplitude of anomalies is almost recovered in the cross-section N-S (Figure 3e). Figures $2 \mathrm{~g} \sim 21$ and $3 \mathrm{c} \sim 3 \mathrm{~d}$ show the distribution of the number of rays along the corresponding profiles. As mentioned above, major structural features obtained in this study are reliable.

\section{Discussion}

Projecting the relocated earthquakes on the velocity profile, it is found that most of them are located at the boundary between high- and low-velocity anomalies (Figures $2 \mathrm{a} \sim 2 \mathrm{~d}$ ). Furthermore, in the Beibu gulf and west Hainan regions most of earthquakes bias toward low-velocity anomalies, while in northeast and southeast Hainan they bias toward high-velocity anomalies. In northeast Hainan the distribution of earthquake hypocenters is consistent with the shape of the northwest oriented Puqian-Qinglan and west-east oriented Wangwu-Wenjiao fault zones, suggesting that the occurrence of these earthquakes may be related to the activities of these faults. In addition, the earthquakes along the Wangwu-Wenjiao fault zone are deeper, and the pattern of high- and low-velocity anomalies bounded along this fault zone extended to a greater depth (Figures 2 and 3). However, both the earthquakes and low-velocity anomalies along the Puqian-Qinglan fault zone are all shallower (Figures 2a and 2b). These results may imply that the Puqian-Qinglan fault zone may be shallower, while the Wangwu-Wenjiao fault zone may be deeper, possibly extend to the Moho discontinuity.

It can be seen clearly from Figures $2 \mathrm{a} \sim 2 \mathrm{c}$ that in the shallow crust, the velocities in north Hainan are much lower than those in central and south Hainan, consistent not only with the geological structure of depressions in north Hainan and uplift in central and south Hainan, but also with the results of the crust thickness that are thicker in central and south Hainan than that in north Hainan, obtained from gravity data and receiver function analyses (LI et al, 2006; Qiu et al, 2002). The low-velocity anomalies from south of the Leizhou peninsula to the whole Leiqiong basin (Figures 2 and 3) are in agreement with the higher geothermal background where the Quaternary volcanism was intensive and once erupted many times (CHEN et al, 1991). 

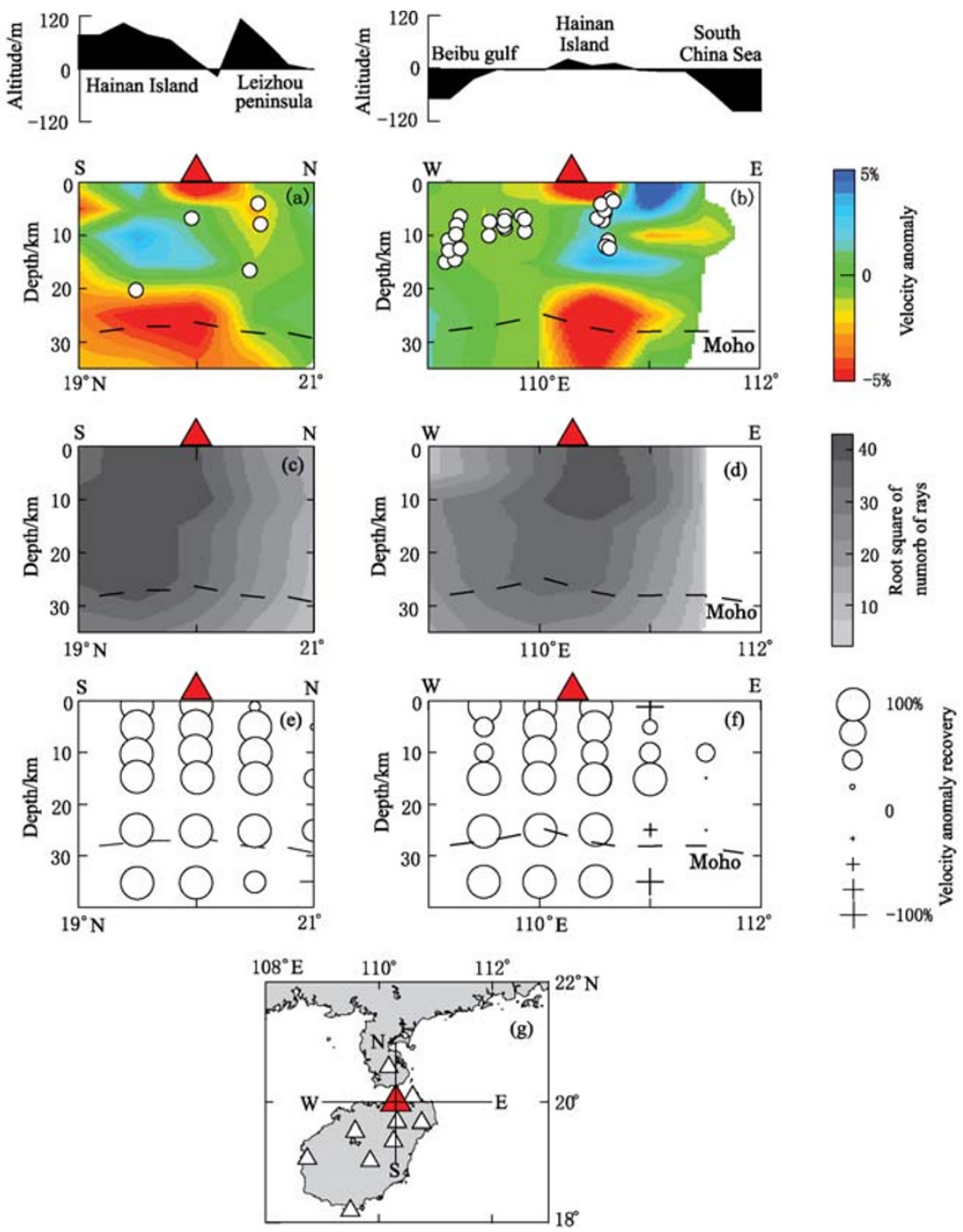

Figure 3 (a) and (b) Cross-sections of 3-D P-wave velocity anomalies under Hainan and adjacent areas; (c) and (d) The number of rays along the cross-sections; (e) and (f) The result of a checkerboard resolution test along the cross-sections; (g) Locations of the cross-sections

In (a) and (b) red and blue colors denote slow and fast velocity anomalies. The velocity perturbation scale is shown on the right of (b). White circles denote the earthquakes. Polygons above (a) and (b) are topographies along the cross-sections. The scale for the number of rays is shown on the right of (d). In (e) and (f) circles and stars denote the symbols of the velocity anomalies inverted wrongly and correctly, respectively, and their sizes denote the ratio of inverted to input anomalies. The scale is shown on the right of (f). Such an expression of the checkerboard resolution test is easy to express the resolution of the cross-section not right passing through the grid nodes in the model. For more details, see LEI and ZHOU (2002) and Lei and Zhao $(2005,2007 \mathrm{a}, \mathrm{b})$. In (a) (f) dashed curves denote the Moho discontinuity along the profiles. In (a) $\sim(\mathrm{g})$ red triangles denote the hotspot. In $(\mathrm{g})$ white triangles denote nine seismic stations in Hainan Island and adjacent areas

By using the first P-wave arrival time data from the Chinese Seismic Network (1985 1997) and the ISC (International Seismological Center) bulletins (1964 1997), LEI and ZHOU (2002) obtained the velocity structure from the surface to $400 \mathrm{~km}$ depth in southwest China and its adja- 
cent areas. They found that there is an obvious low-velocity anomaly around Hainan, though it is located at the edge of the study area and the data coverage is not very good. Liang et al (2004) inverted a velocity model of the uppermost mantle under China and its adjacent areas by using the Pn wave arrival times of the Chinese Seismic Network (1985 1997), the Sichuan-Yunnan regional network (1980 1997), and the ISC bulletins (1964 1997). Their results also show the existence of a low-velocity anomaly in north Hainan. DING et al (2004) also obtained the deep structure in the region by using the receiver function analyses and tomographic technique applied to the data observed from 14 temporary seismic stations installed in volcanic areas in north Hainan in a period of half years from September 2001 to May 2002. The results showed that the velocities were lower in the middle and lower crust in volcanic region of north Hainan, and low velocity anomaly moved toward under the Qiongzhou strait down to the uppermost mantle. These results are similar to those from seismic sounding data along the Baiyan-Jianghong cross-section in the Pleistocene basalt covered areas of the Leiqiong depression (JIA et al, 2006), suggesting that the thinning of the crust and lower velocity anomalies may be related to the multi-stage eruption of volcanic magma from the Cenozoic to the late Quaternary, the underplating and delaminating of the crustal bottom by the mantle, and the crust being in a relatively thermal state (SUN et al, 1988). In this study, a high-resolution velocity model in the region has been obtained by the use of the arrival time data recorded by nine stations in Hainan and adjacent areas since 1999 from the earthquakes occurred around Hainan, and found that obvious low-velocity anomalies in the crust are observed in north Hainan and Leizhou peninsula, which are connected to those in the mantle (Figure 3). This result provides reliable seismological evidence for the hypothesis of the underplating of the mantle to the crust bottom proposed by SUN et al (1988).

\section{Conclusions}

A high-resolution velocity model of the crust in the region has been obtained by the use of the large number of high-quality arrival times recorded by nine seismic stations of the Hainan seismic network. The results showed that there is somewhat correlation between velocity anomalies and geological tectonics in Hainan. The west-east oriented Wangwu-Wenjiao fault zone is a boundary between low-velocity anomalies in north Hainan where mainly exist depressions and high-velocity anomalies in central-south Hainan where mainly exist uplifts. This pattern of anomalies extended to the Moho discontinuity. The low-velocity anomalies only exist down to about $5 \mathrm{~km}$ depth along the northwest oriented fault zones (i.e., Puqian-Qinglan fault zone) in northeast Hainan, suggesting that their depths may be shallower, though they are active.

There are obvious low-velocity anomalies under north Hainan, Leizhou peninsula, and Qiongzhou strait, where the Quaternary volcanism was intensive, and volcanoes once erupted many times, consistent with the higher geothermal background there. These low-velocity anomalies extend from the surface through the Moho discontinuity down to the upper mantle, which provides reliable seismological evidence for the hypothesis of the undeplating of the mantle to the crustal bottom proposed by previous researchers.

Acknowledgments All figures were plotted by using the GMT software (Wessel and Smith, 1995).

\section{References}

CHEN Mo-xiang, XIA Si-gao, YANG Shu-zhen. 1991. Local geothermal anomaly and its formation mechanisms on the Leizhou Penin- 
sula, South China [J]. Scientia Geological Sinica, 4: 369-383 (in Chinese).

CHEN Yun-ping, XI Dao-ying, FAN Xing. 2002. The study on the active faults in Hainan Island by way of fractal theory [J]. Journal of Seismological Research, 25(4): 351-355 (in Chinese)

Courtillot V, Davaille A, Besse J, et al. 2003. Three distinct types of hotspots in the Earth's mantle [J]. Earth Planet Sci Lett, 205: 295-308.

Davies G. 1988. Ocean Bathymetry and mantle convection 1. Large-scale flow and hotspot [J]. J Geophys Res, 93: $10467-10480$.

DING Yuan-zhang, LI Ping, SHI Zhen-liang, et al. 1998. Earthquake Study Collected Works in Northern Hainan Island [M]. Beijing: Seismological Press: 1-299 (in Chinese).

DING Zhi-feng, LI Wei-ping, WU Qing-ju, et al. 2004. The seismic observation and structure study of the crust and mantle in volcanic area of the northern Hainan Island [M]//ZHANG Zhong-Jie, GAO Rui, LU Qing-tian, et al. Research of the Deep Structure and Dynamics in Chinese Mainland: To celebrate academician Teng Jiwen's 50th anniversary of geophysical research. Beijing: Science Press: 846-857 (in Chinese).

HU Jiu-chang, CHEN Jin-yan, HUANG Miao-ying. 1997. The characteristics of the $M_{\mathrm{L}} 5.2$ earthquake in coastal waters of Dongfang in 1995 [J]. South China Journal of Seismology, 17(1): 39-45 (in Chinese).

JIA Shi-xu, LI Zhi-xiong, XU Zhao-fan, et al. 2006. Crustal structural features of the Leiqiong depression in Hainan Province [J]. Chinese J Geophys, 49(5): $1385-1394$ (in Chinese).

JIANG Xiao-dian and LI Wei-ran. 1994. Study on potential earthquake source of the Hainan Island [J]. Journal of Natural Disasters, 3(1): 104-109 (in Chinese).

Lebedev S, Chevrot S, Nolet G, et al. 2000. New seismic evidence for a deep mantle origin of the S. China basalts (the Hainan plume?) and other observations in SE Asia [J] EOS Trans AGU, 81: 48-48.

Lei J and Zhao D. 2005. P-wave tomography and origin of the Changbai intraplate volcano in Northeast Asia [J]. Tectonophysics, 397: 281-295.

Lei J and Zhao D. 2006. Global P-wave tomography: On the effect of various mantle and core phases [J]. Phys Earth Planet Inter, 154: 44-69.

Lei J and Zhao D. 2007a. Teleseismic evidence for a break-off subducting slab under Eastern Turkey [J]. Earth Planet Sci Lett, 257: $14-28$

Lei J and Zhao D. 2007b. Teleseismic P-wave tomography and the upper mantle structure of the central Tien Shan orogenic belt [J]. Phys Earth Planet Inter, 162: 165-185.

LEI Jian-she and ZHOU Hui-lan. 2002. 3-D velocity structure of P wave in the upper mantle beneath Southwestern China and its adjacent areas [J]. Acta Seismologica Sinica, 15(2): 134-142 (in Chinese).

LI Jian-sheng. 1991. Fault structure system and the regional stability in Hainan Island region [J]. Marine Sciences, 3: 19-21 (in Chinese)

LI Zhi-xiong, ZHAO Wen-jun, LIU Guang-xia. 2006. A study on deep crust structures and stress situation of the 1605 Qiongshan strong earthquake [J]. South China Journal of Seismology, 26(1): 28-36 (in Chinese).

Liang C, Song X, Hunag J. 2004. Tomogaphic inversion of Pn travel times in China [J]. J Geophys Res, 109, doi: $10.1029 / 2003 J B 002789$.

Paige C C and Saunders M A. 1982. LSQR: An algorithm for spare linear equations and spare least squares [J]. ACM Trans Math Software, 8: 43-71.

Qiu X, Priestley K, Mckenzie D. 2002. Teleseismic P-waveform receiver function analysis and its application to Qiongzhong station (QIZ) of Hainan Island, NW south Chian sea [J]. J Geosci China, 4(1): 1-8.

Sleep N. 1990. Hotspots and mantle plumes: Some phenomenology [J]. J Geophys Res 95: 6715-6736.

SUN Jian-zhong, FAN Qi-cheng, CHEN Wen-ji. 1988. The study of Quaternary volcanic activity in northern Hainan Island [M]// DING Yuan-zhang, LI Ping, SHI Zhen-liang, et al. Earthquake Study Collected works in northern Hainan Island [M]. Beijing: Seismological Press: 17-25 (in Chinese).

Waldhauser F and Ellsworth W L. 2000. A double-difference earthquake location algorithm: Method and application to the Northern Hayward Fault, California [J]. Bull Seism Soc Amer, 90(6): 1353-1 368.

Wessel P and Smith W. 1995. New version of the Generic Mapping Tools (GMT) version 3.0 released [J]. EOS Trans AGU, 76: 329-329.

Zhao D and Lei J. 2004. Seismic ray path variations in a 3-D global velocity model [J]. Phys Earth Planet Inter, 141: $153-166$.

Zhao D, Hasegawa A, Horiuchi S. 1992. Tomographic imaging of P and S wave velocity structure beneath northeastern Japan [J]. $J$ Geophys Res, 97: 19 909-19928.

Zhao D. 2001. Seismic structure and origin of hotspots and mantle plumes [J]. Earth Planet Sci Lett, 192: 251-265. 